NBER WORKING PAPER SERIES

KEYNESIAN PRODUCTION NETWORKS AND THE COVID-19 CRISIS:

A SIMPLE BENCHMARK

\author{
David Baqaee \\ Emmanuel Farhi \\ Working Paper 28346 \\ http://www.nber.org/papers/w28346 \\ NATIONAL BUREAU OF ECONOMIC RESEARCH \\ 1050 Massachusetts Avenue \\ Cambridge, MA 02138 \\ January 2021
}

Emmanuel Farhi tragically passed away in July, 2020 before this paper was written. Emmanuel was a one-in-a-lifetime friend and collaborator. David Baqaee is responsible for any errors. We thank our discussant Jennifer La'O for her comments. We received support from NSF grant No. 1947611. The views expressed herein are those of the authors and do not necessarily reflect the views of the National Bureau of Economic Research.

NBER working papers are circulated for discussion and comment purposes. They have not been peer-reviewed or been subject to the review by the NBER Board of Directors that accompanies official NBER publications.

(C) 2021 by David Baqaee and Emmanuel Farhi. All rights reserved. Short sections of text, not to exceed two paragraphs, may be quoted without explicit permission provided that full credit, including $(\odot$ notice, is given to the source. 
Keynesian Production Networks and the Covid-19 Crisis: A Simple Benchmark

David Baqaee and Emmanuel Farhi

NBER Working Paper No. 28346

January 2021

JEL No. E0,E24,E3,E4,E5

\begin{abstract}
$\underline{\text { ABSTRACT }}$
The Covid-19 crisis is an unusual and seemingly all-encompassing economic shock. On the one hand, it was unquestionably a negative demand shock that, for fixed prices and incomes, reduced household spending. On the other hand, it was also unquestionably a negative supply shock that reduced firms' ability to maintain production at pre-pandemic prices and quantities. These negative shocks affected different industries differently: whereas some producers easily switched to remote-work and maintained both employment and production, industries that required face-toface contact were forced to reduce production capacity and employment. We consider a strippeddown version of the model presented in Baqaee and Farhi (2020). Despite its simplicity, the model nevertheless allows for an arbitrary input-output network, complementarities in both consumption and production, incomplete markets, downward nominal wage rigidity, and a zerolower bound. In this sense, it contains many of the ingredients typically considered to be important for understanding the economic fallout from Covid-19. Nevertheless, despite allowing for these realistic ingredients, this model has a stark property: factor income shares at the initial equilibrium are global sufficient statistics for the input-output network. This article clarifies clarifies what ingredients must be added to a model if the production network is to play an important role in the propagation of shocks.
\end{abstract}

\author{
David Baqaee \\ Department of Economics \\ University of California at Los Angeles \\ Bunche Hall \\ Los Angeles, CA 90095 \\ and CEPR \\ and also NBER \\ baqaee@econ.ucla.edu \\ Emmanuel Farhi \\ Harvard University
}




\title{
Keynesian Production Networks and the Covid-19 Crisis: A Simple Benchmark
}

\author{
David Baqaee and Emmanuel Farhi*
}

January 19, 2021

The Covid-19 crisis is an unusual and seemingly all-encompassing economic shock. On the one hand, it was unquestionably a negative demand shock that, for fixed prices and incomes, reduced household spending (see, e.g. Chetty et al., 2020). On the other hand, it was also unquestionably a negative supply shock that reduced firms' ability to maintain production at pre-pandemic prices and quantities. These negative shocks affected different industries differently: whereas some producers easily switched to remote-work and maintained both employment and production, industries that required face-to-face contact were forced to reduce production capacity and employment.

The contrasting fates of different industries, as they were buffeted by negative demand and supply shocks, is seen in Figure 1, which is a histogram of the percentage change in industry-level prices from January 2020 to May 2020. Whereas some industries, like oil and gas extraction, petroleum, and most transportation industries cut prices dramatically by tens of percentage points, other industries like food manufacturing, ambulatory health care services, and wholesale traders raised prices by similar magnitudes.

Of course, negative shocks to an individual producer are undesirable, but a key concern that emerged during the pandemic is the possibility that these negative shocks can travel along supply chains. The worry is that production problems can spread like a virus from

*UCLA, Bunche Hall, 315 Portola Plaza, Los Angeles, CA, baqaee@econ.ucla.edu. Emmanuel Farhi tragically passed away in July, 2020 before this paper was written. Emmanuel was a one-in-a-lifetime friend and collaborator. David Baqaee is responsible for any errors. This article was prepared for the 2021 AEA Papers and Proceedings. We thank our discussant Jennifer $\mathrm{La}^{\prime} \mathrm{O}$ for her comments. We received support from NSF grant No. 1947611. 


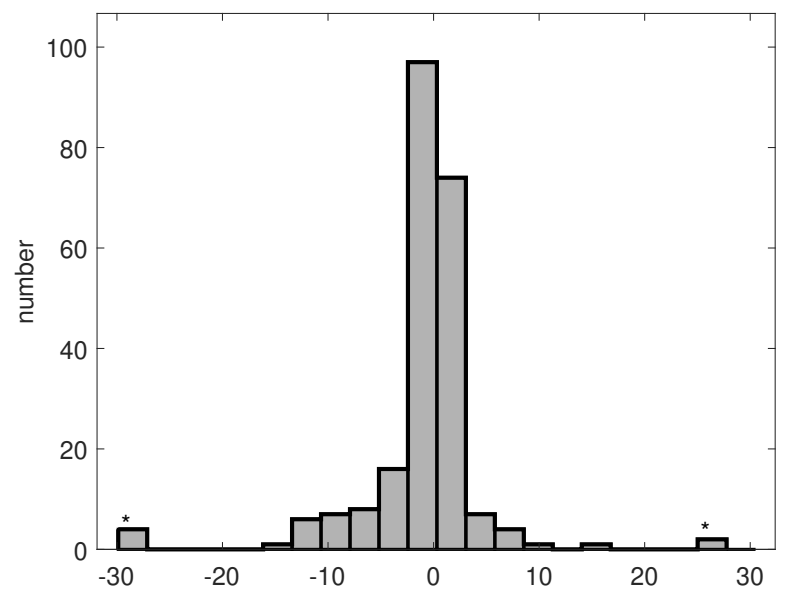

Figure 1: Percentage change in industry-level producer prices from January to May, 2020 from the BLS.

one producer to others, amplifying and broadening the impact of these negative shocks. News articles, particularly during the initial onset of the pandemic, often highlighted domestic and international supply chain problems that hampered and disrupted the supply of many consumer goods and services.

In a recent paper, Baqaee and Farhi (2020b), we study the importance of production networks in amplifying and propagating supply and demand shocks. In this article, we consider a stripped-down version of the model presented in Baqaee and Farhi (2020b). Despite its simplicity, the model we present nevertheless allows for an arbitrary inputoutput network, complementarities in both consumption and production, incomplete markets, downward nominal wage rigidity, and a zero-lower bound. In this sense, the simplified model contains many of the ingredients typically considered to be important for understanding the economic fallout from Covid-19.

Nevertheless, despite allowing for these realistic ingredients, this model has a very stark property: namely, factor income shares at the initial equilibrium are global sufficient statistics for the input-output network. More precisely, the response of welfare, inflation, and sectoral employment to sectoral factor supply and aggregate demand shocks do not depend on the production network conditional on initial factor income shares.

Of course, this does not imply that production networks are therefore not important for understanding the effects of Covid-19. Rather, this result highlights the fact that the role played by input-output linkages is more subtle than one might at first imagine. The mere existence of production networks, even ones with complementarities, is not enough to magnify the effects of negative shocks. In particular, the irrelevance result in this article 
clarifies what ingredients must be added to a model if the production network is to play an important role in the propagation of shocks.

In this short paper, we do not investigate how the economy responds to supply and demand shocks, nor do we show how the network begins to matter once one deviates from the network-irrelevant benchmark. Our goal here is limited to proving conditions under which the network structure is irrelevant. The systematic analysis of how the economy responds to shocks and what changes when we deviate from the conditions that imply network-irrelevance can be found in Baqaee and Farhi (2020b).

\section{Model Sketch}

Consider a general equilibrium model with a set of industries $\mathcal{N}$ and factor markets $\mathcal{G}$. There are two periods: the present and the future. Each period, households are endowed with some factors, and the aggregate endowment of every factor $f \in \mathcal{G}$ is normalized to be one in both periods. In equilibrium, the quantity of a factor that is employed may be less than this endowment $L_{f} \leq 1$.

Households. There is a population of households with identical preferences, and each household owns one unit of only one of the factors. We assume that all non-employment occurs via the extensive margin, so that if some factor $f$ is not fully employed $L_{f}<1$, this means $1-L_{f}$ workers are completely unemployed whilst the other $L_{f}$ are fully employed. Of the $1-L_{f}$ workers who are unemployed, we assume that a fraction $\phi_{f}$ can borrow against their future income, but $1-\phi_{f}$ cannot borrow, and therefore, cannot consume in the present period.

All households have intertemporal preferences given by

$$
\frac{y^{1-1 / \rho}-1}{1-1 / \rho}+\beta \frac{y_{*}^{1-1 / \rho}-1}{1-1 / \rho}
$$

where $y$ represents present consumption and $y_{*}$ future consumption, $\beta$ controls time preferences and $\rho$ is the intertemporal elasticity of substitution. Since employed households and households that can borrow have the same homothetic preferences, we can aggregate these households into a single representative household that we call the Ricardian household. This Ricardian household faces the following intertemporal budget constraint

$$
p^{y} y+\frac{p_{*}^{y} y_{*}}{1+i}=\sum_{f \in \mathcal{G}} w_{f} L_{f}+\sum_{f \in \mathcal{G}} \frac{w_{f}^{*} L_{f}^{*}}{1+i}\left(1-\left(1-L_{f}\right)\left(1-\phi_{f}\right)\right),
$$


where $p^{y}$ and $p_{*}^{y}$ are the price of consumption in the present and future, $i$ is the nominal interest rate, $w_{f}$ and $w_{f}^{*}$ are present and future wages, and $L_{f}$ and $L_{f}^{*}$ are present and future employment levels. This equation simply states that the net present value of consumption must equal the net present value of income for the representative Ricardian agent. The right-hand side accounts for the fact that not all of aggregate income earned in the future goes to the representative Ricardian household, since the non-Ricardian households will be earning income in the future.

Preferences over final goods within the period are given by a CES aggregator

$$
y=\left(\sum_{j \in \mathcal{N}} \omega_{0 j} c_{j}^{\frac{\theta-1}{\theta}}\right)^{\frac{\theta}{\theta-1}}
$$

where $\mathcal{N}$ is the set of all goods, $c_{j}$ is the quantity of good $j$ consumed by the household, $\omega_{0 j}$ are household taste parameters for good $j$, and $\theta$ is the elasticity of substitution.

Denote aggregate real consumption in the current and future period by $Y$ and $Y_{*}$. Log differencing the consumption Euler equation for the representative Ricardian consumer yields

$$
\Delta \log Y=-\rho \Delta \log p^{y}+\Delta \log \zeta+\Delta \log \Theta
$$

where

$$
\zeta=\left(\frac{\beta(1+i)}{p_{*}^{y}}\right)^{-\rho} Y_{*}
$$

and

$$
\Theta=\sum_{f} w_{f}^{*} L_{f}^{*}\left(1-\left(1-L_{f}\right)\left(1-\phi_{f}\right)\right) .
$$

Equation (3) is the aggregate demand (AD) curve - a downward sloping relationship between output and the price level. The terms $\Delta \log \zeta$ and $\Delta \log \Theta$ are shifters of the AD curve.

Producers. The economy features an arbitrary production network. The production of each industry $i \in \mathcal{N}$ is given by

$$
y_{i}=\left(\sum_{j \in \mathcal{N}} \omega_{i j} x_{i j}^{\frac{\theta-1}{\theta}}+\sum_{f \in \mathcal{F}} \omega_{i f} c_{i f}^{\frac{\theta-1}{\theta}}\right)^{\frac{\theta}{\theta-1}},
$$

where $y_{i}$ is the quantity of good $i$ produced, $x_{i j}$ are intermediate inputs and $l_{i f}$ are factor inputs used by industry $i$. The parameters $\omega_{i j}$ and $\omega_{i f}$ determine the endogenous network 
structure of production in this economy. A crucial assumption is that the elasticity of substitution $\theta$ in production is uniform across all producers and is the same as the one in consumption

Market Equilibrium. We assume that goods markets clear with perfect competition and flexible prices. In particular, goods-market clearing implies that the total quantity of every good $j$ that is produced equals the total quantity that is used:

$$
y_{j}=\sum_{i \in \mathcal{N}} x_{i j}+c_{j}
$$

Unlike the goods market, we allow for the possibility that factor markets may fail to clear due to downward wage rigidity. Denote total demand for factor $f$ by

$$
\sum_{i \in \mathcal{N}} l_{i f}=L_{f}
$$

Factor market equilibrium is described by

$$
\bar{w}_{f} \leq w_{f,} \quad L_{f} \leq \bar{L}_{f}, \quad\left(w_{f}-\bar{w}_{f}\right)\left(L_{f}-\bar{L}_{f}\right)=0 .
$$

The first equation ensures that wages in factor market $f$ cannot fall below some exogenous lower-bound $\bar{w}_{f}$. The second equation ensures that the quantity of factor $f$ employed is less than some exogenous upper-bound $\bar{L}_{f}$. The third equation ensures that either wages are equal to their lower-bound or quantities are equal to their upper-bound. To make wages in a factor market flexible, we can simply set the lower-bound on wages in that market to $-\infty$. We do not need to specify equilibrium in the bond market or how the nominal interest rate is set.

Supply and Demand Shocks. In this article, we restrict our attention to two particular ways in which Covid-19 affected the economy.

1. Covid-19 may have affected intertemporal preferences for consumption by reducing the utility value of consuming in the present relative to tomorrow. We model this via shocks to the aggregate demand shifter $\Delta \log \zeta$, and refer to such shocks as aggregate demand shocks. In principle, these could be shocks to the nominal interest rate, or changes in expectations about future output and prices. More relevant for the pandemic, $\Delta \log \zeta$ could also be a discount factor shock that causes households to prefer to delay consumption in anticipation of the arrival of vaccines. 
2. Covid-19 affected the quantity of labor that can safely be used in production. We model this via changes in the upper-bound of labor available in each factor market $\Delta \bar{L}_{f}<0$. In other words, these are reductions in the quantity of each factor that can be employed in the absence of any nominal rigidities. For example, a reduction in this upper-bound can represent some of the consequences of social distancing and stay-at-home orders. More broadly, these shocks can represent reduced willingness by households to supply labor or reduced willingness by firms to employ labor. The former could be due to health concerns whereas the latter could be due to reduced capacity or legal liability concerns. We refer to these as factor supply shocks since these shocks contract the economy's production possibility set.

Of course, the pandemic likely had many other effects on the economy including changes to the composition of household demand across different sectors as well as changes in sectoral total factor productivity. Since network-irrelevance does not hold for these shocks, we abstract from them here; for an analysis of these other shocks, see Baqaee and Farhi (2020b).

\section{Sufficient Statistics for the Network}

To state our sufficient statistics result, we must define some new notation.

Notation. The input-output matrix of this economy is a $(1+\mathcal{N}+\mathcal{G}) \times(1+\mathcal{N}+\mathcal{G})$ matrix $\Omega$ whose $i j$ th element is equal to $i$ 's expenditures on inputs from $j$ as a share of its total income/revenues. So, when $i \in \mathcal{N}$

$$
\Omega_{i j} \equiv \frac{p_{j} x_{i j}}{p_{i} y_{i}} .
$$

The first row and column of $\Omega$ correspond to the household sector, the next $\mathcal{N}$ rows and columns correspond to the goods-producing industries, and the last $\mathcal{G}$ rows and columns correspond to the factors of production. The input-output matrix $\Omega$ records the direct exposures of one producer to another. We define the Leontief inverse matrix as

$$
\Psi \equiv(I-\Omega)^{-1}=I+\Omega+\Omega^{2}+\ldots
$$

The Leontief inverse matrix $\Psi$ records instead the direct and indirect exposures through the supply chains in the production network.

Denote nominal household expenditures (GDP) by $E$, and the Domar weight $\lambda_{i}$ of 
producer $i$ by

$$
\lambda_{i} \equiv \frac{p_{i} y_{i}}{E} .
$$

Denote the share of aggregate income accruing to factor $f$ by

$$
\lambda_{f}=\frac{w_{f} L_{f}}{\sum_{g \in \mathcal{G}} w_{g} L_{g}}=\frac{w_{f} L_{f}}{E} .
$$

The accounting identity

$$
\lambda_{i} E=\Omega_{1 i} E+\sum_{j \in \mathcal{N}} \Omega_{j i} \lambda_{j} E
$$

links the factor income shares to the Leontief inverse via

$$
\lambda_{f}=\Psi_{1 f}=\sum_{j \in \mathcal{N}} \Omega_{1 j} \Psi_{j f},
$$

where $\Omega_{1 j}=\left(p_{j} c_{j}\right) / E$ is the share of good $j$ in household expenditure.

Global Sufficient Statistics Denote the value of any variable $X$ at the initial equilibrium by $\bar{X}$. The following theorem describes the sense in which the production network is irrelevant for the propagation of shocks in this economy.

Theorem 1. Consider an aggregate demand shock $\Delta \log \zeta$ and a vector of factor supply shocks $\Delta \log \bar{L}=\left(\Delta \log \bar{L}_{1}, \ldots, \Delta \log \bar{L}_{\mathcal{G}}\right)$. Then

$$
\Delta \log Y(\Delta \log \bar{L}, \Delta \log \zeta, \bar{\Omega})=\Delta \log Y\left(\Delta \log \bar{L}, \Delta \log \zeta, \bar{\Omega}^{\prime}\right)
$$

for every $\bar{\Omega}$ and $\bar{\Omega}^{\prime}$ as long as

$$
\bar{\lambda}_{f}=\bar{\Psi}_{1 f}=\bar{\Psi}_{1 f}^{\prime}=\bar{\lambda}_{f}^{\prime}, \quad \text { for every } f \in \mathcal{G} .
$$

Furthermore, the initial factor income shares $\bar{\lambda}_{f}$ are also sufficient statistics for equilibrium changes in the aggregate price index $\Delta \log p^{y}$, factor wages $\Delta \log w_{f}$, factor quantities $\Delta \log L_{f}$, and changes in factor income shares $\Delta \log \lambda_{f}$.

In other words, the response of output, inflation and employment with respect to sectoral factor supply shocks $\Delta \log \bar{L}$ and aggregate demand shocks $\Delta \log \zeta$ do not depend on the production network beyond the factor income shares in the initial pre-shock equilibrium. In particular, an economy without intermediates is isomorphic to one with intermediates as long as both economies have the same initial factor income shares. Fur- 
thermore, since the lower-bound on wages can be $-\infty$, Theorem 1 also applies to models with flexible wages and prices.

Theorem 1 clarifies what ingredients are necessary if the production network is to matter. We need to introduce either (1) shocks that affect intermediate inputs as well as factors, that is, TFP shocks, or (2) sector-specific demand shocks (as opposed to aggregate demand shocks), or (3) allow elasticities of substitution to vary across producers and consumers in the economy, or (4) allow for sticky prices.

Intuitively, employment, and therefore output, is determined by how the production network directs the flow spending across different factor markets. In response to changes in relative prices, producers and consumers substitute away from some inputs and towards others. When elasticities of substitution in production and consumption are all the same, these substitutions all happen at the same rate, so that demand for each factor ultimately depends on the factor's price relative to the consumer price index and the details of the input-output matrix drop out.

Theorem 1 can be proved by showing that the equilibrium conditions do not depend on the input-output matrix $\bar{\Omega}$ beyond the initial factor shares $\bar{\lambda}$. To see this, use $\Delta \log E=$ $\Delta \log p^{y}+\Delta \log Y$ to rearrange (3) to get

$$
\Delta \log E=(1-\rho) \Delta \log p^{y}+\Delta \log \zeta+\Delta \log \Theta
$$

Next, since every good is ultimately made up of factors, changes in the CPI depend only on changes in factor prices. That is,

$$
\Delta \log p^{y}=\frac{1}{1-\theta} \log \left(\sum_{f \in \mathcal{G}} \bar{\lambda}_{f} \exp \left((1-\theta) \Delta \log w_{f}\right)\right) .
$$

Finally, factor demand can be shown to be isoelastic with elasticity $\theta$ in the price of each factor relative to the $\mathrm{CPI}$, so that

$$
\Delta \log w_{f}=\frac{1}{\theta}\left(\Delta \log E-\Delta \log L_{f}\right)+\frac{\theta-1}{\theta} \Delta \log p^{y} .
$$

Equilibrium in the factor market is determined by combining factor demand (13) with the factor supply relationship (5). Taken together, these equations pin down all the relevant variables without requiring any information about the input-output network $\bar{\Omega}$ beyond $\bar{\lambda}$. This means that when the assumptions of Theorem 1 are satisfied, a multi-sector analysis that abstracts from input-output linkages, along the lines of Guerrieri et al. (2020), is without loss of generality. 


\section{Conclusion}

We provide conditions under which the responses of sectoral employment, output, and inflation to sectoral supply shocks or aggregate demand shocks do not depend on the production network beyond the factor income shares in the initial pre-shock equilibrium. This network-irrelevance result holds despite the fact that the model features complementarities in consumption and production, as well as downward nominal wage rigidity and market incompleteness. This result clarifies the ingredients that must be added to a model, if the production network is to matter. In this short paper, we do not analyze how the economy responds to negative supply and demand shocks, including how the production network plays a prominent role once the assumptions of Theorem 1 are relaxed. For studies that analyze and quantify such comparative statics see Baqaee and Farhi (2020b) and Baqaee and Farhi (2020a) and the references therein.

\section{References}

Baqaee, David, and Emmanuel Farhi. 2020a. "Nonlinear Production Networks with an Application to the Covid-19 Crisis."

Baqaee, David, and Emmanuel Farhi. 2020b. "Supply and Demand in Disaggregated Keynesian Economies with an Application to the Covid-19 Crisis."

Chetty, Raj, John N Friedman, Nathaniel Hendren, Michael Stepner, et al. 2020. "How did covid-19 and stabilization policies affect spending and employment? a new realtime economic tracker based on private sector data." National Bureau of Economic Research.

Guerrieri, Veronica, Guido Lorenzoni, Ludwig Straub, and Iván Werning. 2020. "Macroeconomic Implications of COVID-19: Can Negative Supply Shocks Cause Demand Shortages?" National Bureau of Economic Research. 